\title{
Investigation and optimization of friction stir welding process parameters of stir cast $\mathrm{AA6082} / \mathrm{ZrO}_{2} / \mathrm{B}_{4} \mathrm{C}$ composites
}

\author{
Umar Mohamed J. ${ }^{1, *}$, Palaniappan PL. K. ${ }^{2}$, Maran P. ${ }^{2}$, Pandiyarajan R. ${ }^{3}$ \\ ${ }^{1}$ Research Scholar, Department of Mechanical Engineering, Anna University, Chennai 600025, Tamil Nadu, India \\ ${ }^{2}$ Dept. of Mechanical Engineering, Thiagarajar College of Engineering, Madurai 625015, Tamil Nadu, India \\ ${ }^{3}$ Dept. of Mechanical Engineering, K.L.N College of Engineering, Potapalayam 630612, Tamil Nadu, India
}

In the present investigation, aluminium-based alloy (AA6082) is stir-casted with $3 \% \mathrm{ZrO}_{2}$ and $5 \% \mathrm{~B}_{4} \mathrm{C}$ reinforcement particulates to fabricate Aluminium Metal Matrix Hybrid Composites (AMMHCs) which are further friction-stir welded at different welding conditions to develop a welded joint with optimum ultimate tensile strength (UTS) and microhardness. This newly developed AMMHC will find its specific application as bulkhead partitions in the hull of a ship due to its excellent properties, such as lower weight, higher specific strength, superior resistance to wear, and lower thermal expansion coefficient than that of AA6061 and AA5083 composites. The friction-welded butt joints performance of $\mathrm{AA} 6082 / 3 \% \mathrm{ZrO}_{2} / 5 \% \mathrm{~B}_{4} \mathrm{C}$ is generally determined by varying the FSW process parameters such as tool rotational speed (TRS), welding speed (WS), axial load (AL), tool tilt angle (TTA), tool pin profile (TPP), shoulder diameter (SD), etc. In the present work, the empirical relationships are established between parameters highly influencing FSW process (TRS, WS, and AL) and their responses (UTS and weld nugget microhardness (WNH)). The desirability approach is employed for predicting the optimal UTS and WNH. The corresponding values of input process parameters are TRS of $1030.95 \mathrm{rpm}$, WS of $38.5 \mathrm{~mm} / \mathrm{min}$, and AL of $5.88 \mathrm{kN}$. The calculated UTS and WNH for the present investigation are $239.98 \mathrm{MPa}$ and $94.2 \mathrm{HV}$, respectively, and these values are consistent with the results of validation experiments.

Keywords: friction stir welding; ultimate tensile strength; microhardness; response surface methodology; Box-Behnken design; optimization; desirability approach

\section{Introduction}

Friction-stir welded aluminium matrix composite (AMC) joints find application in the areas of automobile, naval and aeronautical engineering, due to their attractive characteristics like higher strength, lower density, excellent corrosion resistance, better thermal conductivity, low thermal expansion, and better dimensional stability with good strength to mass ratio [1-6]. AMC, being an ideal material for this new generation, also faces many problems in welding by conventional fusion welding owing to the reaction between matrices and particulates of reinforcement that lead to the development of secondary brittle phases in the molten pool of the weld or reinforcement breakdown in the molten pool of metal [7].

*E-mail: umarmjamaludeen@gmail.com
To achieve efficient defect-free weld (less cracking, no distortion, decreased porosity, etc.) on AMC's, friction stir welding (FSW) is considered to be a less expensive and more effective solid-state welding process for AMCs [8]. FSW has numerous advantages like green cleaning, low distortion and residual stresses, no fumes and spatter, and no requirement of filler material and shielding gas [9]. These attractive features of FSW have made many researchers start and continue their research in the application areas of aviation, aerospace, automotive, and shipbuilding industries. They are developing advanced techniques and newer materials for base matrix and reinforcement to optimize the performance of the FS welded joints. Advanced techniques are needed for the optimization of maximizing mechanical properties, such as UTS, WHN, etc. Response surface methodology (RSM) is one of the most accurate methods for determining 
the optimum welding parameters with less time, material, and labor efforts [10].

Mishra et al. [7] focused on the single response optimization of FSW process parameters by employing a modified milling machine on AA6082T6 to find the parametric influence of TRS, WS, tool shoulder diameter, and pin profile on UTS of the FS welded joints. They reported that the TRS of $1200 \mathrm{rpm}$, WS of $30 \mathrm{~mm} / \mathrm{min}$, and tool of cylindrical threaded pin profile with a shoulder diameter of $16 \mathrm{~mm}$ gave the optimum results for UTS of 244.86 MPa. Arab et al. [8] carried out the optimization studies on the FSW of AA6082-T6 plates using the Taguchi method. They determined the most important factors like UTS and microhardness (HV) through the L9 orthogonal array. They reported that the optimal process parameters for maximum UTS (202.05 MPa) were obtained as TRS (1400 rpm) and WS (125 mm/min). It was also found that the combination of TRS (1400 rpm) and WS $(160 \mathrm{~mm} / \mathrm{min})$ resulted in an optimum microhardness value ( $82 \mathrm{HV}$ ).

Khaki et al. [9] discussed the multi-objective optimization of the FSW process parameters, like the TRS, WS, ratio of shoulder diameter to pin diameter ( $\mathrm{D} / \mathrm{d}$ ratio), and the shoulder base angle for AA6061-T6 to maximize the UTS and the surface hardness. They reported that maximum UTS of 190 $\mathrm{MPa}$ and maximum surface hardness of $74.3 \mathrm{HV}$ were attained at a TRS of $800 \mathrm{r} / \mathrm{m}$, a D/d ratio of 3, a shoulder base angle of $7^{\circ}$, and a WS of $80 \mathrm{~mm} / \mathrm{min}$. Vijayan et al. [10] proposed the RSM based GRA to predict the important parameters for FSW of AA2024 and AA6061. The optimal parameters predicted for the maximum UTS (141 MPa) and elongation (12\%) were TRS of $1700 \mathrm{rpm}$, WS of $60 \mathrm{~mm} / \mathrm{min}$, AL of $6 \mathrm{kN}$, and pin shape of the square profile. Bayazid et al. [11] discussed the optimization of FSW of AA 6063 and 7075 alloys and predicted the influence of FSW factors, such as TRS, WS, and plate position on metallurgical and mechanical characteristics of the alloys using the Taguchi method. They concluded that UTS (157 MPa) was achieved at a TRS of $1600 \mathrm{rpm}$ and WS of $120 \mathrm{~mm} / \mathrm{min}$.

Chanakyan et al. [12] discussed the GRA on TRS, WS, and various tool pin diameters for FSW of different AA2024 and AA6061 joints. They found that the TRS and WS significantly influenced the responses. Jain et al. [13] examined the influence of four FSW important parameters (TRS, WS, TPP, and SD) on different FSW of AA6082 T6 and AA5083-O alloys utilizing the Taguchi's grey relational weight method. They concluded from the results that the optimum UTS was achieved for the TRS of $1200 \mathrm{rpm}$, WS of $35 \mathrm{~mm} / \mathrm{min}$, and SD of $16 \mathrm{~mm}$.

Periyasamy et al. [14] examined the FSW of AA6061 metal matrix reinforced with SiCp and they optimized the input factors such as TRS, WS, and AL using the desirability approach. They measured the responses like UTS, notch tensile strength (NTS), and WNH. They reported that the weld made by the TRS (1370 rpm), WS $(88.9 \mathrm{~mm} / \mathrm{min})$, and AL $(9.6 \mathrm{kN})$ produce the optimum NTS, UTS, and WNH of $201 \mathrm{MPa}, 265 \mathrm{MPa}$, and $114 \mathrm{HV}$, respectively. Ahmed et al. [15] conducted the FSW optimization of process parameters for AA6082/ $\mathrm{Al}_{2} \mathrm{O}_{3}$ employing the ANOVA method and RSM to find out the optimum UTS of the welded joints. They reported that according to the ANOVA the wt. $\%$ of $\mathrm{Al}_{2} \mathrm{O}_{3}$ was the major parameter compared to TRS. They concluded from the mathematical model that the optimum UTS was $105 \mathrm{MPa}$ for TRS (1000 rpm) and $\mathrm{Al}_{2} \mathrm{O}_{3}(5 \%$ as reinforcement).

Kumar et al. [16] developed the regression models for FSW process parameters such as TRS, WS, AL, and wt.\% of AlNp reinforcement on AA6061 alloy to calculate the UTS and Percentage Elongation (PE). Deepandurai et al. [17] investigated the effect of FS welding parameters like TRS, WS, AL, and percentage of $\mathrm{SiC}$ reinforcement on AA7075 using fuzzy grey relational analysis (FGRA) to measure the responses, like UTS and percentage elongation (PE). They reported optimal UTS of $285.75 \mathrm{MPa}$ and PE of $6.98 \%$ attained at a TRS of $1150 \mathrm{rpm}$, WS of $40 \mathrm{~mm} / \mathrm{min}$, AL of $6 \mathrm{kN}$, and wt. \% of reinforcement of $20 \%$ of SiC by the highest grey fuzzy reasoning grade (HGFRG). They also reported that the analysis using ANOVA for multi-response cases indicated that percent of reinforcement was the utmost significant parameter.

Bhushan et al. [18] organized the study and 
optimized the parameters of FS welding for AA6082/10\%SiC MMC plates. They reported that the optimal parameters for the optimum UTS were attained at the TRS of $1800 \mathrm{rpm}$, WS of $100 \mathrm{~mm} / \mathrm{min}$, and the TTA of $2^{\circ}$. Salih et al. [19] investigated the FSW of AA6092/17.5\%SiC-T6 AMC to evaluate the changes in the microstructural and mechanical characteristics of AMC with varying TRS and WS. They reported that the maximum UTS and the efficiency of the joint (75\%) of the welded joints were obtained at a TRS of $1500 \mathrm{rpm}$ and a WS of $100 \mathrm{~mm} / \mathrm{min}$. Pandiyarajan et al. [20] employed the desirability approach to optimize the FSW parameters like TRS, WS and AL for instantaneous enhancement of UTS and macrohardness of $\mathrm{AA} 6061 / \mathrm{ZrO}_{2} / \mathrm{C}$ welded composites. They reported that the maximum UTS of $190 \mathrm{MPa}$ and macrohardness of $50 \mathrm{HRB}$ were obtained at TRS around (853 rpm), WS (48 mm/min), and AL $(5 \mathrm{kN})$.

Research is being carried out by numerous researchers to optimize the responses (UTS, WNH, etc.) of the FSW joints of different aluminium alloys reinforced with different ceramic particulates by selecting suitable process parameters, using newer techniques on newer and advanced materials. In this present work, investigations have been performed to develop a new hybrid composite made of AA6082 as a base material reinforced with the $\mathrm{ZrO}_{2}$ and $\mathrm{B}_{4} \mathrm{C}$ to increase the mechanical and metallurgical characteristics of the FS welded joints. Response surface methodology (RSM), Box-Behnken design, and desirability approach have been employed to create empirical relationships between FSW parameters (TRS, WS, and $\mathrm{AL}$ ) and the two responses (UTS and WNH) and to determine the optimal welding conditions that will produce FSW joints with optimized UTS and $\mathrm{WNH}$.

\section{Methodology}

\subsection{Response surface methodology (RSM)}

Researchers as well as engineers always desire to determine the input process parameters or factors at which output response would attain the optimum values. The optimum values would be either a maximum or minimum of a particular function which depends upon the input process parameters. Response surface methodology (RSM) is one of the most important mathematical and statistical techniques used for building the empirical model. For industrial as well as in experimental circumstances, independent variables can be quantitatively expressed as shown in equation 1 . Then, these independent parameters can have a functional relationship as follows:

$X=\psi\left(Y_{1}, Y_{2}, Y_{3}, \ldots Y_{n}\right) \pm$ error from experiments

Between the response, $\mathrm{X}$, and quantitative parameters, $Y_{1}, Y_{2}, Y_{3}, \ldots Y_{n}$, function $\psi$ is called the response surface or function. The response surface responds to the given set of independent parameters. For a given set of independent parameters, a characteristic surface is responded. The approximation using a polynomial can be done satisfactorily for unknown $\psi$ within the experimental region. In this examination work, the RSM has been employed for the formulation of a mathematical model using multiple regression equation for friction stirred joining of $\mathrm{AA} 6082 / 3 \% \mathrm{ZrO}_{2} / 5 \% \mathrm{~B}_{4} \mathrm{C}$ for determining the quality characteristics of weldments. To adopt the RSM, the independent parameter is considered as a surface for which a mathematical model is fitted. The ultimate tensile strength (UTS) and weld nugget microhardness (WNH) of the FSW of AA $6082 / 3 \% \mathrm{ZrO}_{2} / 5 \% \mathrm{~B}_{4} \mathrm{C}$ are the functions of tool rotational speed (TRS), welding speed (WS), and axial load (AL). The surface can be expressed as follows:

$$
U T S=f(T R S, W S, A L)
$$

$$
W N H=f(T R S, W S, A L)
$$

The second-order regression equation used to represent the response surface is given by:

$$
X=a_{0}+\Sigma a_{i} x_{i}+\Sigma a_{i i} x_{i}^{2}+\Sigma a_{i j} x_{i} x_{j}+\varepsilon
$$


The second-order polynomial regression was employed to present the $\mathrm{X}$ response surface, where $\mathrm{a}_{0}$ is the average response; $\mathrm{a}_{\mathrm{i}}, \mathrm{a}_{\mathrm{ii}}$ and $\mathrm{a}_{\mathrm{ij}}$ are coefficients dependent on the major and interaction effects of the parameters and $\epsilon$ is the statistical error.

\subsection{Box-Behnken design}

In the present work, three process parameters with three levels have been considered during the friction stir welding of $\mathrm{AA} 6082 / 3 \% \mathrm{ZrO}_{2} / 5 \% \mathrm{~B}_{4} \mathrm{C}$ and they are TRS, WS, and AL. The correlation of process parameters with UTS and WNH of welded joints are generally developed in the design before actual welding. In this work, the Box-Behnken design approach has been used for developing the correlation and to find out optimal design parameters for optimizing the UTS and WNH of FS welded joints. Three-factorial Box-Behnken experimental design has been selected for determining the correlation between the response parameters (UTS and $\mathrm{WNH}$ ) and the input parameters (TRS, WS, and $\mathrm{AL})$. These most influencing process parameters of FSW on the output responses have been identified with their levels using Box-Behnken model design and it is presented in Table 1. The levels of the process parameters are denoted as -1 (low), 0 (medium), and 1 (high). According to BoxBehnken experimental design, 17 experiments are needed to be conducted. Table 2 presents the actual design matrix.

Table 1. The level of process parameters.

\begin{tabular}{lccc}
\hline \multicolumn{1}{c}{ Level } & -1 & 0 & 1 \\
\hline \hline Tool rotational speed (rpm) & 800 & 1000 & 1200 \\
Welding speed (mm/min) & 25 & 37.5 & 50 \\
Axial load $(\mathrm{kN})$ & 4 & 6 & 8 \\
\hline
\end{tabular}

\subsection{Desirability approach}

The desirability approach is one of the most widely employed techniques for multiple response optimization processes. The main function of the desirability approach is that it provides importance to every single response like UTS or WNH. It converts these single responses into the dimensionless parameter called desirability function and assigns them numbers between 0 and 1 . The multiple responses like UTS and WNH are converted into a dimensionless measure of performance by the overall desirability function. In this present investigation, multiple responses, such as tensile strength and hardness are converted into a dimensionless parameter. The overall desirability function is given by the following equation 5 :

$$
\text { Desirability function, } F=\left(d_{1 *} d_{2 * \cdots *} d_{n}\right)^{1 / n}
$$

where $d_{n}$ indicates the desirability of the response and $\mathrm{n}$ is the number of responses.

\subsection{Optimization of process parameters}

Optimization of FSW process parameters is performed using Design-Expert software. Both numerical and graphical optimization methods are employed by setting the desired goals for each input parameter and response. In the numerical optimization process, all the goals are combined into the overall desirability function. This optimization process sets the maximum and minimum limits for each factor and finds out the response that will optimize the objective function. In case of graphical optimization with multiple responses, this graphical method is used to determine the interaction effects of process parameters on responses and it is shown clearly in 2D contour plot and 3D contour plot. When dealing with more number of responses, numerical optimization is highly recommended to run first to determine a feasible region, whereas the graphical optimization helps to display a feasible response area and finally, the shaded region represents the unfit optimization criteria. Fig. 1 displays the flow chart for optimization process of Design- Expert software.

\section{Experimental}

\subsection{Stir casting process of $\mathrm{AA6082}-\mathrm{ZrO}_{2}$ - $\mathrm{B}_{4} \mathrm{C}$}

AA 6082 alloy is first sliced and heated in a graphite crucible of an electric furnace which is maintained at $850{ }^{\circ} \mathrm{C}$. The primary $\left(3 \% \mathrm{ZrO}_{2}\right)$ and secondary $\left(5 \% \mathrm{~B}_{4} \mathrm{C}\right)$ reinforcement particulates are preheated in a baking oven at $350{ }^{\circ} \mathrm{C}$ to remove 
Table 2. Design matrix for FSW.

\begin{tabular}{cccc}
\hline Run & Tool rotational speed $(\mathrm{rpm})$ & Welding speed $(\mathrm{mm} / \mathrm{min})$ & Axial load $(\mathrm{kN})$ \\
\hline \hline 1 & 1000 & 25 & 4 \\
2 & 800 & 37.5 & 4 \\
3 & 1200 & 37.5 & 4 \\
4 & 1000 & 50 & 4 \\
5 & 800 & 25 & 6 \\
6 & 1200 & 25 & 6 \\
7 & 1000 & 37.5 & 6 \\
8 & 1000 & 37.5 & 6 \\
9 & 1000 & 37.5 & 6 \\
10 & 1000 & 37.5 & 6 \\
11 & 1000 & 37.5 & 6 \\
12 & 800 & 50 & 6 \\
13 & 1200 & 50 & 6 \\
14 & 1000 & 25 & 8 \\
15 & 800 & 37.5 & 8 \\
16 & 1200 & 37.5 & 8 \\
17 & 1000 & 50 & 8 \\
\hline
\end{tabular}

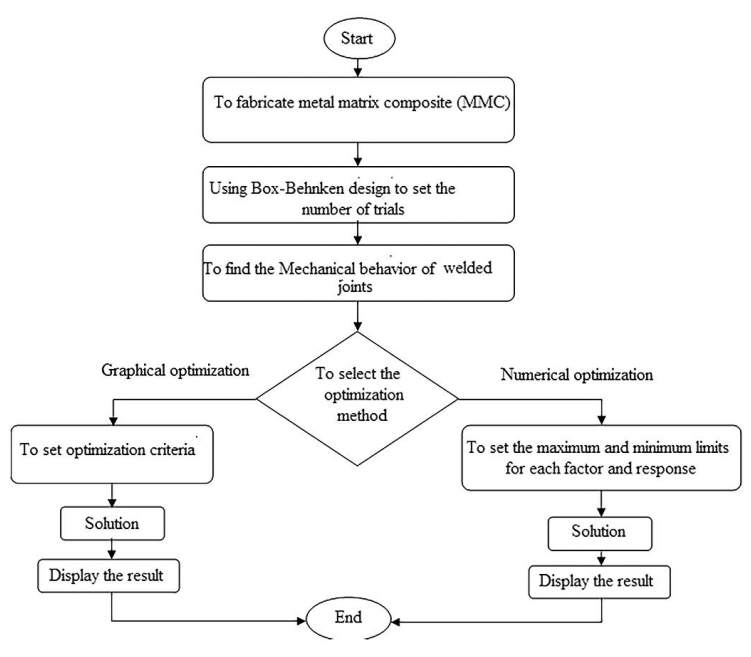

Fig. 1. Flow chart for the optimization process of Design-Expert software.

the moisture content of the reinforcement particulates. The preheated $\left(\mathrm{ZrO}_{2}\right.$ and $\left.\mathrm{B}_{4} \mathrm{C}\right)$ particulates are provided to the molten aluminum AA6082 alloy. The molten matrix of AA6082 along with reinforcement particulates of $\mathrm{ZrO}_{2}$ and $\mathrm{B}_{4} \mathrm{C}$ is stirred with a mechanical stirrer for 10 to 15 minutes at a speed of $600 \mathrm{rpm}$ [21]. This stirring process provides a uniform and homogeneous distribution of reinforcement particulates in the molten metal. After stirring, the molten metal is poured into a cast iron rectangular mold of dimensions $100 \mathrm{~mm}$ (length) $\times 50 \mathrm{~mm}$ (breadth) $\times 6 \mathrm{~mm}($ depth $)$.

\subsection{Tool fabrication for friction stir weld- ing}

The material selected for manufacturing the non-consumable friction stir welding tool is high carbon high chromium steel or $\mathrm{D}_{2}$ tool steel. The chemical composition of this $\mathrm{D}_{2}$ tool steel is shown in Table 3. This tool is manufactured by having a square pin profile. The microhardness of this FSW tool is improved from $52 \mathrm{HRC}$ to $65 \mathrm{HRC}$ by the process of heat treatment, i.e. by heating the tool to a temperature around $800{ }^{\circ} \mathrm{C}$. The dimensions of the FSW fabricated tool are represented in Fig. 2a and the photograph of the FSW tool is shown in Fig. 2b. 
Table 3. Chemical composition of high carbon high chromium or $\mathrm{D}_{2}$ Tool Steel.

\begin{tabular}{llllllllllll}
\hline Elements & $\mathrm{C}$ & $\mathrm{Mn}$ & $\mathrm{Si}$ & $\mathrm{Co}$ & $\mathrm{Cr}$ & $\mathrm{Mo}$ & $\mathrm{V}$ & $\mathrm{P}$ & $\mathrm{Ni}$ & $\mathrm{Cu}$ & $\mathrm{S}$ \\
\hline \hline Content [\%] & $1.4-1.6$ & 0.6 & 0.6 & 1 & $11-13$ & $0.7-1.2$ & 1.1 & 0.03 & 0.3 & 0.25 & 0.03 \\
\hline
\end{tabular}
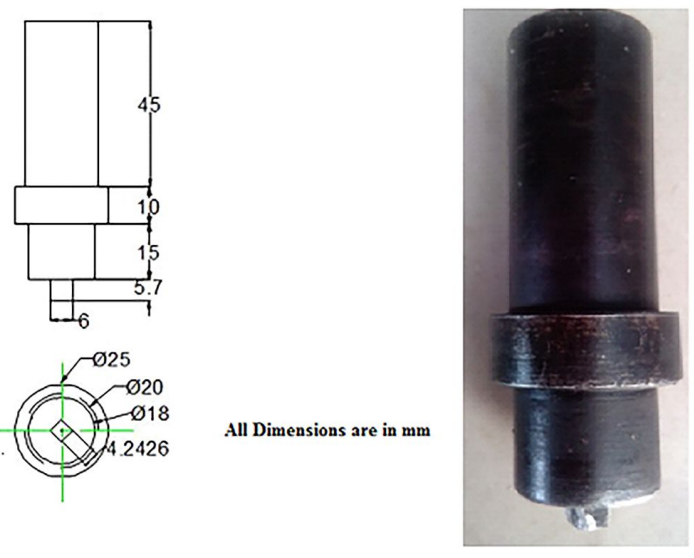

Fig. 2. Details of FSW tool geometry: (a) 2-D drawing of FSW tool; (b) photograph of FSW tool.

\subsection{Friction stir welding}

Two AA $6082 / 3 \% \mathrm{ZrO}_{2} / 5 \% \mathrm{~B}_{4} \mathrm{C}$ stir cast plates of dimensions $100 \mathrm{~mm} \times 50 \mathrm{~mm} \times 6 \mathrm{~mm}$ are fixed firmly in position on the table of the FSW machine using mechanical clamping. The FSW tool with a square pin profile is fixed rigidly to the rotational spindle. During welding, the rotating FSW tool is moved vertically downward for penetration and longitudinally for the joining of plates by employing the control panel. The axial load is provided by the FSW tool on the plates by a hydraulic system. The TRS, WS, and AL are considered as major influencing process parameters in this current study. The selected ranges of process parameters and their levels are presented in Table 1. The maximum limit of a process parameter is represented as +1 and its minimum limit is represented as -1 . Friction stir welding is performed to fabricate the butt joints for all 17 runs as presented in Table 2 .

\subsection{Metallurgical and mechanical testing}

After performing the friction stir welding, the welded joint is tested for its quality by conducting the tensile test, hardness tests, and metallographic tests, such as OM, SEM, etc. The test specimens are prepared using a wire-cut EDM as per ATSM standard. For tensile testing, the test specimens are cut perpendicular to the welded joint according to ASTM E8M-04 standards and the tests are conducted using a computer-controlled universal testing machine (Make: Associated Scientific Engg. Works, Model: F-100 and Capacity: Max 5 Ton). The UTS of the tensile specimen is calculated at $1 \mathrm{~mm} / \mathrm{min}$ crosshead speed and the test results of UTS are presented in Table 4. Weld nugget hardness testing has also been performed on Micro Vickers Hardness Tester (Make: Wilson Wolpert, Germany). Microhardness test specimens are fabricated according to the ASTM E10-08. The microhardness test is performed at three locations, namely, one on the weld nugget zone (WNZ) and two on the heat-affected zone (HAZ). The transverse section of the welded plate is considered for the preparation of metallographic samples. These samples are exposed to color etchant with a reagent $\left(4 \mathrm{~g}\right.$ of $\mathrm{KMnO}_{4}$ and $1 \mathrm{~g}$ of $\mathrm{NaOH}$ dissolved in $100 \mathrm{ml}$ distilled water). The metallurgical structure of samples is detected using an optical metallurgical microscope (De-Wintor Inverted Trinocular Metallurgical Microscope) and a scanning electron microscope (FEI SEM-Apreo Model).

\section{Results and discussion}

\subsection{Mechanical characterization}

\subsubsection{Developing empirical relationships}

The Box-Behnken model is employed to construct an experimental design matrix as presented in Table 2. FSW on hybrid composites has been conducted by altering the process parameters, such as TRS, WS, and AL according to the experimental design matrix shown in Table 4. Test specimens for the tensile and microhardness tests have been prepared from the fabricated welded joints as per 
Table 4. Experimental design matrix and results of tensile strength and hardness.

\begin{tabular}{cccccc}
\hline Run & $\begin{array}{c}\text { Tool rotational } \\
\text { speed [rpm] }\end{array}$ & $\begin{array}{c}\text { Welding speed } \\
{[\mathrm{mm} / \mathrm{min}]}\end{array}$ & $\begin{array}{c}\text { Axial load } \\
{[\mathrm{kN}]}\end{array}$ & $\begin{array}{c}\text { Tensile strength } \\
{[\mathrm{MPa}]}\end{array}$ & $\begin{array}{c}\text { Weld nugget } \\
\text { microhardness [HV] }\end{array}$ \\
\hline \hline 1 & 1000 & 25 & 4 & 193 & 76 \\
2 & 800 & 37.5 & 4 & 179 & 76 \\
3 & 1200 & 37.5 & 4 & 210 & 73 \\
4 & 1000 & 50 & 4 & 225 & 81 \\
5 & 800 & 25 & 6 & 181 & 70 \\
6 & 1200 & 25 & 6 & 227 & 79 \\
7 & 1000 & 37.5 & 6 & 251 & 93 \\
8 & 1000 & 37.5 & 6 & 233 & 95 \\
9 & 1000 & 37.5 & 6 & 230 & 95 \\
10 & 1000 & 37.5 & 6 & 239 & 94 \\
11 & 1000 & 37.5 & 6 & 233 & 95 \\
12 & 800 & 50 & 6 & 182 & 77 \\
13 & 1200 & 50 & 6 & 215 & 76 \\
14 & 1000 & 25 & 8 & 198 & 76 \\
15 & 800 & 37.5 & 8 & 186 & 77 \\
16 & 1200 & 37.5 & 8 & 196 & 75 \\
17 & 1000 & 50 & 8 & 189 & 82 \\
\hline
\end{tabular}

ASTM standards. UTS and WNH were measured from each test specimen to develop the empirical mathematical relations. The UTS and WNH of the FSW of $\mathrm{AA} 6082 / 3 \% \mathrm{ZrO}_{2} / 5 \% \mathrm{~B}_{4} \mathrm{C}$ were the functions of TRS, WS, and AL. The surface can be expressed as given in equation 2 and equation 3 and also the second-order polynomial (regression) equation used to represent the response surface given by equation 4 .

Initially, the quadratic model is developed. ANOVA is employed to find out the significant responses and interaction terms. F-statistic is used to evaluate the factor of significance. The statistical analyses such as p-value, F-value, degree of freedom, sum of squares, mean sum of squares, coefficient of variation, determination coefficient, adjusted determination of the coefficient, etc have been used. The percentage of contributions for each factor is estimated based on the sum of squares attained from the ANOVA. A quadratic polynomial equation is developed which has both independent and dependent variables and their characteristics are learned using ANOVA. The final regression relations to calculate the UTS and $\mathrm{WNH}$ of FS welded joint for $\mathrm{AA} 6082 / 3 \% \mathrm{ZrO}_{2} / 5 \% \mathrm{~B}_{4} \mathrm{C}$ are expressed as in equation 6 and equation 7 :

$$
\begin{aligned}
& U T S=+237.20+15.00 x A+1.50 x B-4.75 x C \\
& -3.25 x A x B-5.25 x A x C-10.25 x B x C-22.22 x A^{\wedge} 2 \\
& -13.72 x B^{\wedge} 2-22.22 x C^{\wedge} 2
\end{aligned}
$$

$$
\begin{aligned}
& W N H=+94.40+0.38 x A+1.88 x B+0.50 x C \\
& -2.50 x A x B+0.25 x A x C+0.25 x B x C-11.20 x A^{\wedge} 2 \\
& -7.70 x B^{\wedge} 2-7.95 x C^{\wedge} 2
\end{aligned}
$$

The acceptability of the final developed regression relationships is confirmed by the ANOVA technique. It confirms the acceptance of the developed model if the determined value of the F- ratio of the developed model is less than the standard $\mathrm{F}$ ratio value from the $\mathrm{F}$ table under the desired level of confidence (say $95 \%$ ) [10]. 
Table 5. ANOVA results for UTS.

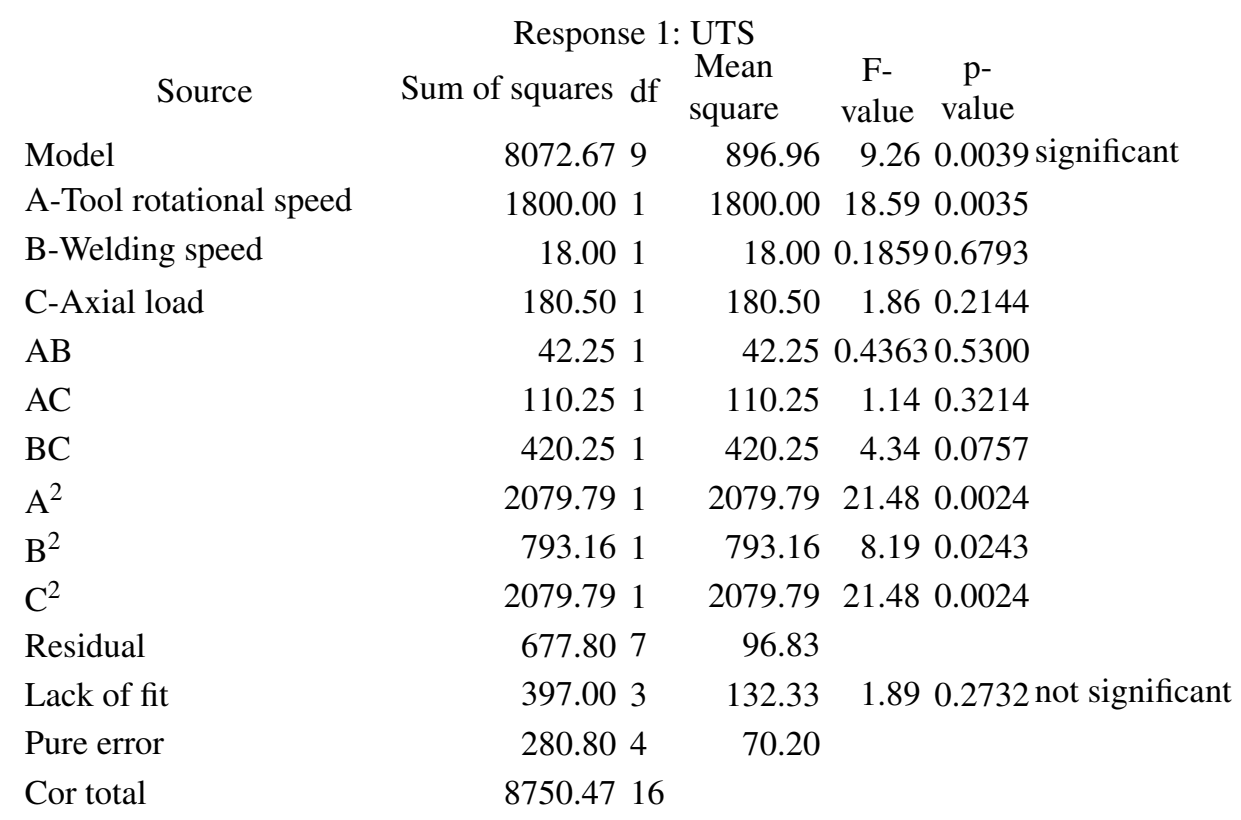

Table 6. ANOVA results for microhardness.

\begin{tabular}{|c|c|c|c|c|}
\hline \multicolumn{5}{|c|}{ Response 2: Microhardness } \\
\hline Source & Sum of squares df & $\begin{array}{l}\text { Mean } \\
\text { square }\end{array}$ & $\begin{array}{c}\text { F- } \\
\text { value }\end{array}$ & $\mathrm{p}$-value \\
\hline Model & 1218.119 & 135.35 & 30.61 & $<0.0001$ significant \\
\hline A-Tool rotational speed & 1.131 & 1.13 & 0.2544 & 0.6295 \\
\hline B-Welding speed & 28.131 & 28.13 & 6.36 & 0.0397 \\
\hline C-Axial load & 2.001 & 2.00 & 0.4523 & 0.5228 \\
\hline $\mathrm{AB}$ & 25.001 & 25.00 & 5.65 & 0.0490 \\
\hline $\mathrm{AC}$ & 0.25001 & 0.2500 & 0.0565 & 0.8189 \\
\hline $\mathrm{BC}$ & 0.25001 & 0.2500 & 0.0565 & 0.8189 \\
\hline$A^{2}$ & 528.171 & 528.17 & 119.46 & $<0.0001$ \\
\hline$B^{2}$ & 249.641 & 249.64 & 56.46 & 0.0001 \\
\hline$C^{2}$ & 266.121 & 266.12 & 60.19 & 0.0001 \\
\hline Residual & 30.957 & 4.42 & & \\
\hline Lack of fit & 27.753 & 9.25 & 11.56 & 0.0193 significant \\
\hline Pure error & 3.204 & 0.8000 & & \\
\hline Cor total & 1249.0616 & & & \\
\hline
\end{tabular}

\subsubsection{The effect of the FSW parameters on the Ultimate tensile strength (UTS) responses (UTS and WNH) \\ The effect of FSW parameters on UTS is rep- \\ In this section, the interaction effects of two resented in the perturbation plot (Fig. 3) for an op- input parameters on the responses are considered timized design. From the plot, it is clear that re- with the third parameter kept at a medium level. sponse changes when each factor moves away from}


the common or reference points keeping all other factors constant at that reference point. It is also clear from the plot that the TRS is the most dominating factor on UTS followed by WS and AL.

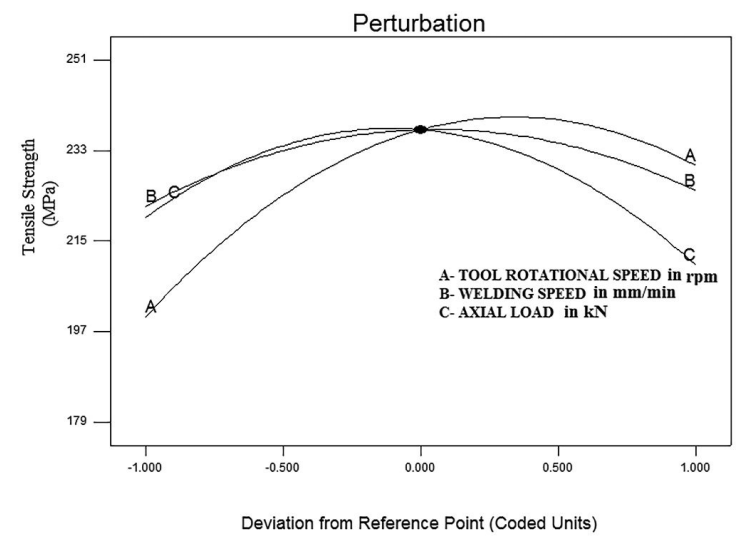

Fig. 3. Perturbation plot representing the effect of FSW parameters on the UTS of FSW joint.

Fig. 4, Fig. 5 and Fig. 6 present the interaction effects of TRS, WS, and AL on the UTS. The effect of the TRS and WS on UTS by keeping AL $6 \mathrm{kN}$ is shown in the $2 \mathrm{D}$ and $3 \mathrm{D}$ contour plot (Fig. 4a and Fig. $4 \mathrm{~b})$. The tensile strength (MPa) is represented as a concentric circle and the optimum value is obtained in the center of the contour plot (Fig. 4a and Fig. 4b). From the plot, it is seen that the optimum UTS of $240 \mathrm{MPa}$ is obtained at a TRS of $1000 \mathrm{rpm}$ and a WS of $37.5 \mathrm{~mm} / \mathrm{min}$. The UTS will tend to decrease or increase when the TRS and WS deviate from the mentioned values.

The interaction effect of AL along with TRS at constant WS of $37.5 \mathrm{~mm} / \mathrm{min}$ is shown in Fig. 5. From the $2 \mathrm{D}$ and $3 \mathrm{D}$ plots, it is evident that the optimum UTS is attained around $240 \mathrm{MPa}$ at a TRS of $1000 \mathrm{rpm}$ and an AL of $6 \mathrm{kN}$.

The interaction effect of AL along with WS at a constant TRS of $1000 \mathrm{rpm}$ is shown in Fig. 6. From the $2 \mathrm{D}$ and $3 \mathrm{D}$ contour plots, it is clearly shown that the approximate value of the optimum UTS of $240 \mathrm{MPa}$ is obtained at a WS of $37.5 \mathrm{~mm} / \mathrm{min}$ and an $\mathrm{AL}$ of $6 \mathrm{kN}$.

\section{Weld nugget microhardness (WNH)}

The effect of FSW process parameters on WNH is represented in the perturbation plot (Fig. 7) for an optimized design. WNH should be higher than

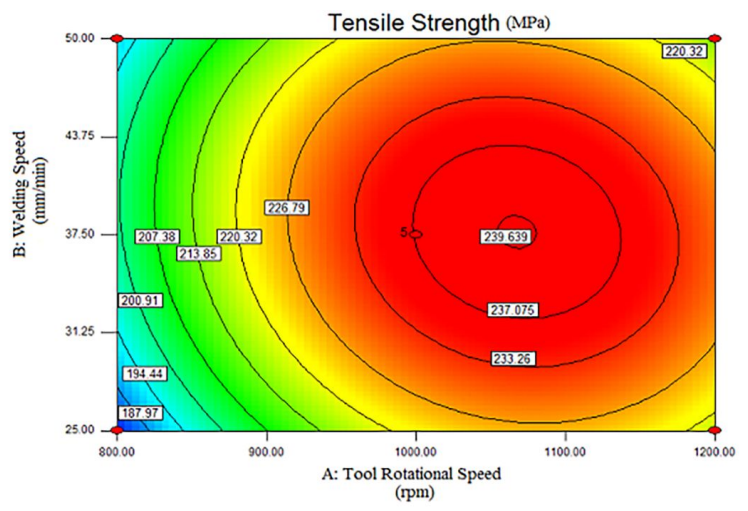

(a)

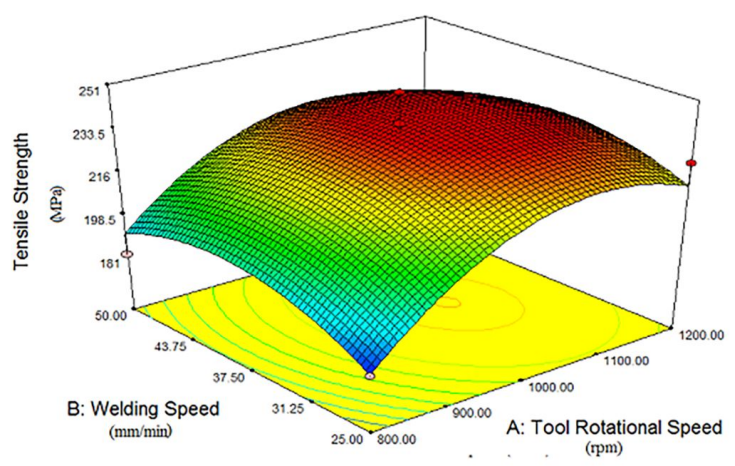

(b)

Fig. 4. Contour plots representing the effect of TRS and WS on UTS of FSW joint: (a) 2D contour plot; (b) $3 \mathrm{D}$ contour plot.

that of base metal at any working level of TRS. The microhardness of base metal AA6082 is $77.5 \mathrm{HV}$ and it is always lower as compared to the stir zone (94.2 HV).

Fig. 8, Fig. 9 and Fig. 10 present the interaction effect of TRS, WS, and AL on the WNH. Fig. 8a and Fig. $8 \mathrm{~b}$ illustrate the effect of TRS and WS on WNH keeping the AL constant at $6 \mathrm{kN}$. WNH (HV) is represented as a concentric ellipse and optimum WNH value is attained at the center of the contour plot (Fig. 8a and Fig. 8b). From the plot, it is clearly shown that the optimum WNH of $94 \mathrm{HV}$ is obtained at a TRS of $1000 \mathrm{rpm}$ and a WS of $37.5 \mathrm{~mm} / \mathrm{min}$.

The interaction effect of AL along with TRS at a constant WS of $37.5 \mathrm{~mm} / \mathrm{min}$ is shown in Fig. 9. From the 2D and 3D plots, it is evident that the optimum WNH is obtained around $94 \mathrm{HV}$ at a TRS of $1000 \mathrm{rpm}$. 


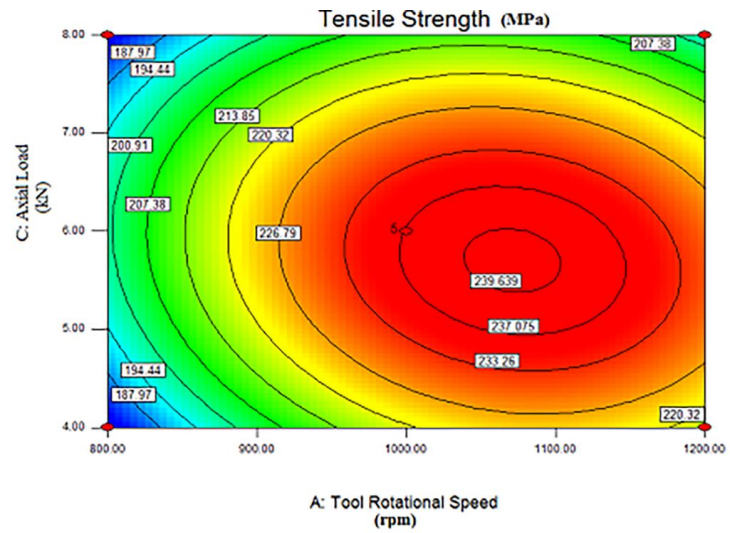

(a)

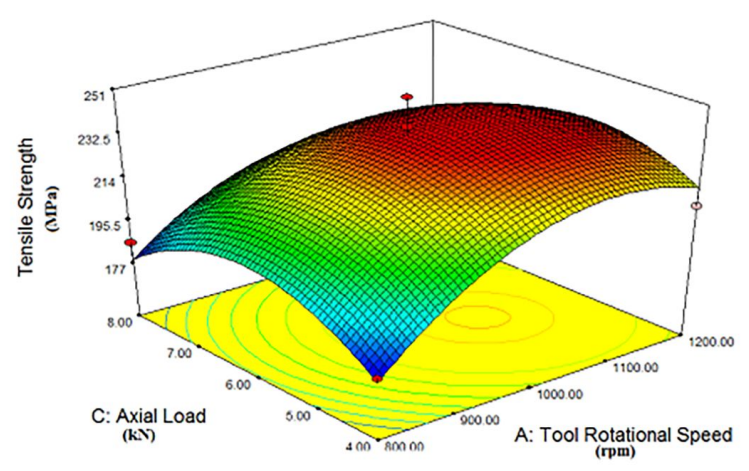

(b)

Fig. 5. Contour plots representing the effect of TRS and AL on UTS of FSW joint: (a) 2D contour plot; (b) 3D contour plot.

The interaction effect of AL along with WS at a constant TRS of $1000 \mathrm{rpm}$ is shown in Fig. 10. From the 2D and 3D plots, it is clearly seen that the optimum WNH of $94 \mathrm{HV}$ is obtained at a WS of $37.5 \mathrm{~mm} / \mathrm{min}$ and an AL of $6 \mathrm{kN}$.

\subsubsection{Results of optimization}

1. After conducting the optimization study for achieving the desired mechanical property of the welded joint, the following optimum welding conditions have been selected using optimization criteria as shown in Table 7. From the results obtained from experiments and optimization, it is very clear that the TRS should be around $1000 \mathrm{rpm}$ to attain optimum UTS and WNH, showing that these responses mainly depend on

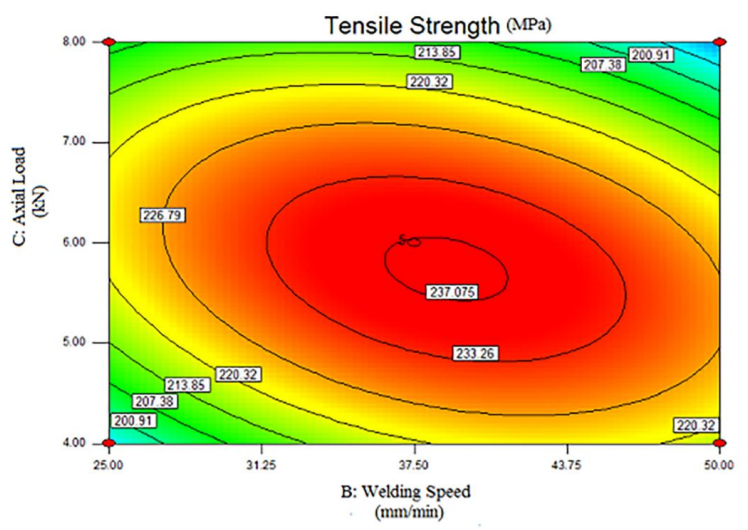

(a)

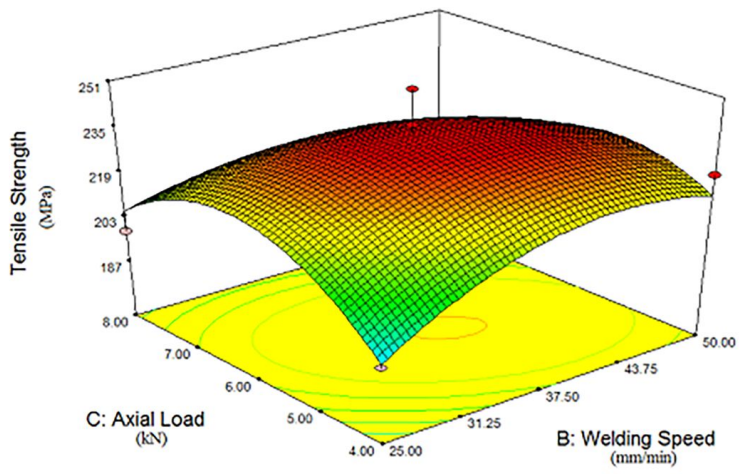

(b)

Fig. 6. Contour plots representing the effect of WS and AL on UTS of FSW joint: (a) 2D contour plot; (b) $3 \mathrm{D}$ contour plot.

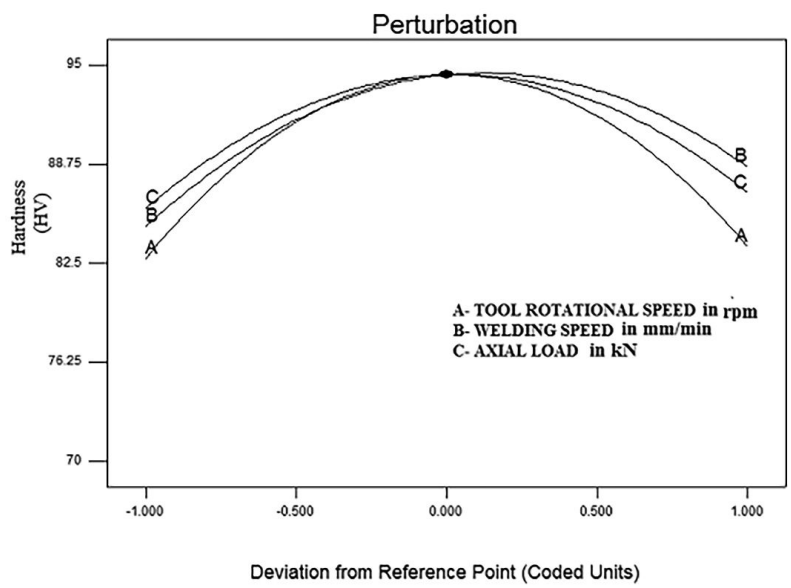

Fig. 7. Perturbation plot representing the effect of FSW parameters on WNH. 


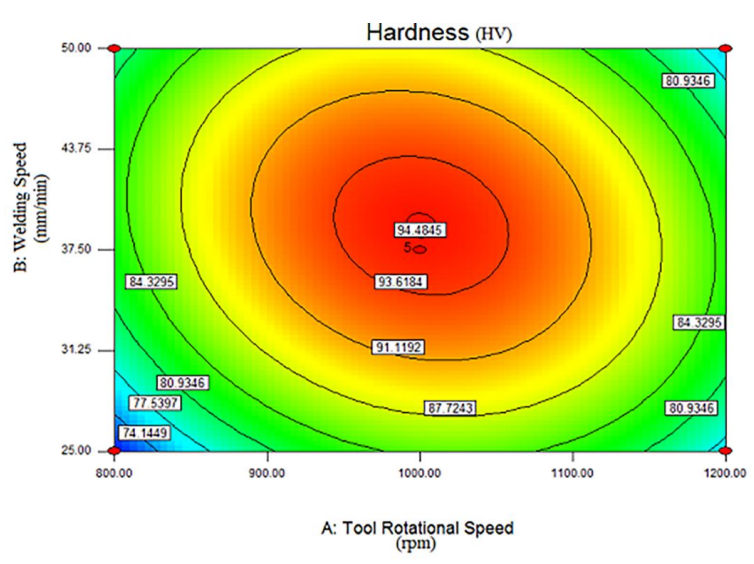

(a)

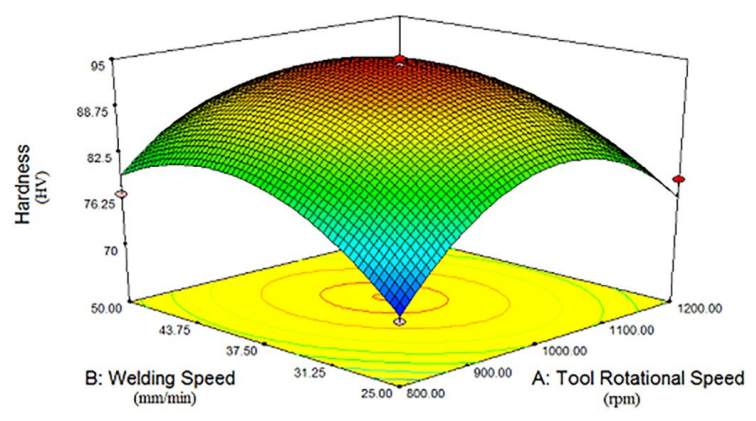

(b)

Fig. 8. Contour plots representing the effect of TRS and WS on WNH: (a) 2D contour plot; (b) 3D contour plot.

TRS compared to other input parameters. Fig. 11a to Fig. 11d show the contour plots and overlay plot, which predict the optimum UTS of $239.28 \mathrm{MPa}$ and WNH of 94.2 HV obtained at the optimum welding conditions such as TRS of $1030.95 \mathrm{rpm}$, WS of $38.5 \mathrm{~mm} / \mathrm{min}$, and AL of $5.88 \mathrm{kN}$.

\subsubsection{Validation of the developed model}

The model developed by the desirability approach is validated with experimental results and the errors are calculated for all 17 runs as given in Table 2. Table 8 represents the actual value, predicted value, and error in percentage for UTS and weld nugget hardness. The actual values are found by conducting the experiments and the predicted values are calculated from the empirical equations developed by the design expert software.

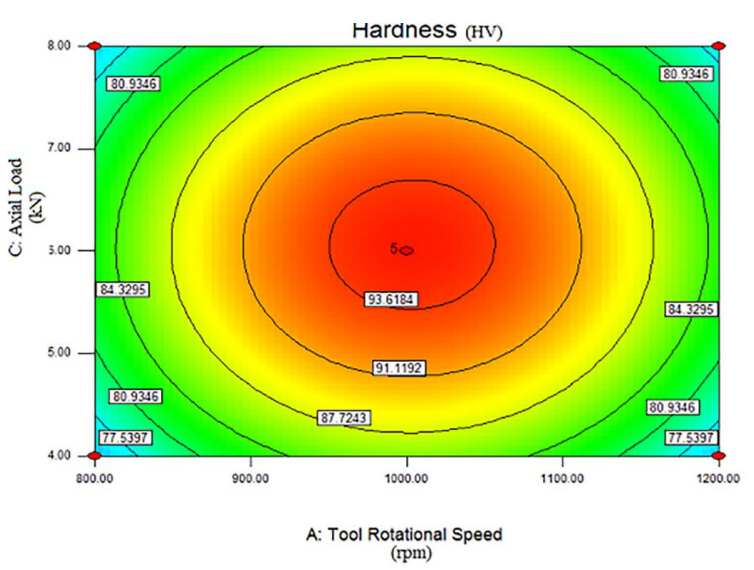

(a)

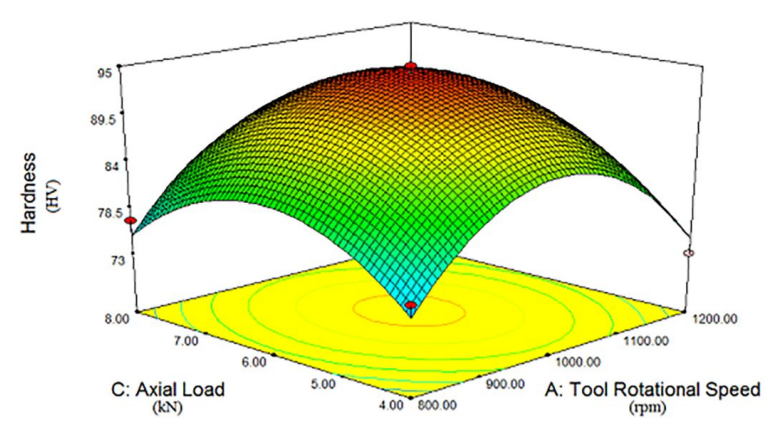

(b)

Fig. 9. Contour plots representing the effect of TRS and $\mathrm{AL}$ on WNH: (a) 2D contour plot; (b) 3D contour plot.

The percentage of error is in the range of -5.82 to +4.71 for UTS. Similarly, the percentage of error for WNH is in the range of -0.327 to +3.14 . Hence, it is clear that the newly developed model has predicted the values of UTS and WNH very close to the experimental results.

Table 9 presents the results of validation experiments. The model is also validated for the predicted optimal welding conditions. Three confirmation experiments have been performed with a TRS of $1030.95 \mathrm{rpm}$, WS of $38.5 \mathrm{~mm} / \mathrm{min}$, and an AL of $5.88 \mathrm{kN}$. The maximum percentage of error for the prediction of optimum UTS and WNH are -1.55 and -1.91 , respectively.

\subsection{Microstructural characterization}

Fig. 12a shows the presence of coarse grains in the base composite material 
Table 7. Optimization criteria used in this work.

\begin{tabular}{lcccc}
\hline \multicolumn{1}{c}{ Process parameters/responses } & Goal & Minimum limit & Maximum limit & Importance \\
\hline \hline Tool rotational speed & is in range & 800 & 1200 & 3 \\
Welding speed & is in range & 25 & 50 & 3 \\
Axial load & is in range & 4 & 8 & 3 \\
Tensile strength & maximize & 179 & 251 & 5 \\
Hardness & maximize & 70 & 95 & 5 \\
\hline
\end{tabular}

Table 8. Experimental results and values predicted from design expert software for all numbers of runs.

\begin{tabular}{ccccccc}
\hline \begin{tabular}{c} 
Run \\
\cline { 2 - 6 }
\end{tabular} & $\begin{array}{c}\text { Actual } \\
\text { value }\end{array}$ & $\begin{array}{c}\text { Predicted } \\
\text { value }\end{array}$ & $\begin{array}{c}\text { Error in } \\
\%\end{array}$ & $\begin{array}{c}\text { Actual } \\
\text { value }\end{array}$ & $\begin{array}{c}\text { Predicted } \\
\text { value }\end{array}$ & Error in \% \\
\hline \hline 1 & 193 & 194.25 & +0.64 & 76 & 76.625 & +0.82 \\
2 & 179 & 177.25 & -0.99 & 76 & 74.625 & -1.84 \\
3 & 210 & 217.75 & 3.56 & 73 & 74.875 & +2.50 \\
4 & 225 & 217.75 & -3.33 & 81 & 79.875 & -1.41 \\
5 & 181 & 181.5 & +0.28 & 70 & 70.75 & +1.06 \\
6 & 227 & 218 & -4.13 & 79 & 76.5 & -3.27 \\
7 & 251 & 237.2 & -5.82 & 93 & 94.4 & +1.48 \\
8 & 233 & 237.2 & +1.77 & 95 & 94.4 & -0.64 \\
9 & 230 & 237.2 & +3.04 & 95 & 94.4 & -0.64 \\
10 & 239 & 237.2 & -0.76 & 94 & 94.4 & +0.42 \\
11 & 233 & 237.2 & +1.77 & 95 & 94.4 & -0.64 \\
12 & 182 & 191 & +4.71 & 77 & 79.5 & +3.14 \\
13 & 215 & 214.5 & -0.23 & 76 & 75.25 & -1.00 \\
14 & 198 & 205.25 & +3.53 & 76 & 77.125 & +1.46 \\
15 & 186 & 178.25 & -4.35 & 77 & 75.125 & -2.50 \\
16 & 196 & 197.75 & +0.88 & 75 & 76.375 & +1.80 \\
17 & 189 & 187.75 & -0.67 & 82 & 81.375 & -0.77 \\
\hline
\end{tabular}

$\left(\mathrm{AA} 6082 / 3 \% \mathrm{ZrO}_{2} / 5 \% \mathrm{~B}_{4} \mathrm{C}\right)$ and it also shows the presence of dendrite structure due to stir casting technique as well as the dispersion of $\mathrm{ZrO}_{2}$ particles in the metal matrix. Fig. 12b represents the macrostructural analysis of the FS welded joint. The four different zones of FSW, weld nugget zone (WNZ), thermomechanically affected zone (TMAZ), heat affected zone (HAZ), and unaffected zone (base material) are seen in the cross weld microstructure of FS welded MMC joints as shown in Fig. 12b to Fig. 12d. It also shows the presence of different microstructure and grain sizes in WNZ, TMAZ, and HAZ due to different heating and cooling conditions in FSW. It is seen that the weld nugget zone has finer grains compared to TMAZ, HAZ, and unaffected zone. This photomicrograph also shows the existence of fine recrystallized structures in the WNZ. The coarse grain structure as seen in the base composite material (Fig. 12a) changes to fine grain structure owing to mechanical stirring action of FSW tool and it is seen in Fig. 12d.

Fig. 13a to Fig. 13d represent the SEM micrographs of base composite material and FS welded composite. Fig. 13a shows the grain size and distribution of $\mathrm{ZrO}_{2}$ and $\mathrm{B}_{4} \mathrm{C}$ in the base 
Table 9. Validation of test results.

\begin{tabular}{cccccccccc}
\hline \multicolumn{2}{c}{$\begin{array}{c}\text { Run Tool rotational Welding speed Axial load } \\
\text { speed [rpm] }\end{array}$} & $\begin{array}{c}\text { UTS } \\
{[\mathrm{mm} / \mathrm{min}]}\end{array}$ & $\begin{array}{c}\text { [MPa] } \\
{[\mathrm{kN}]}\end{array}$ & $\begin{array}{c}\text { Ectual value Predicted value } \\
\text { in \% }\end{array}$ & $\begin{array}{c}\text { Actual value } \\
\text { Actugget microhardness (HRC) }\end{array}$ & $\begin{array}{c}\text { Error } \\
\text { Predicted value }\end{array}$ & in \% \\
\hline \hline 1 & 1030.95 & 38.50 & 5.88 & 242 & 239.28 & -1.14 & 95 & 94.2 & -0.85 \\
2 & 1030.95 & 38.50 & 5.88 & 239 & 239.28 & +0.12 & 94 & 94.2 & +0.21 \\
3 & 1030.95 & 38.50 & 5.88 & 243 & 239.28 & -1.55 & 96 & 94.2 & -1.91 \\
\hline
\end{tabular}

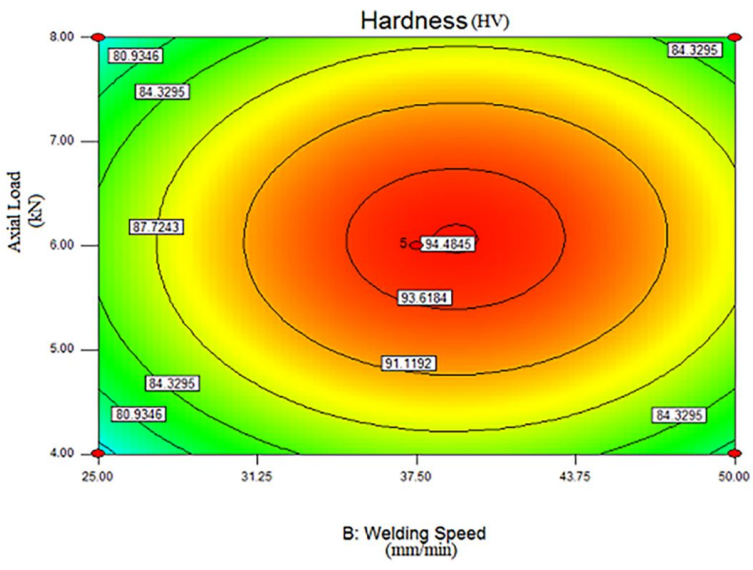

(a)

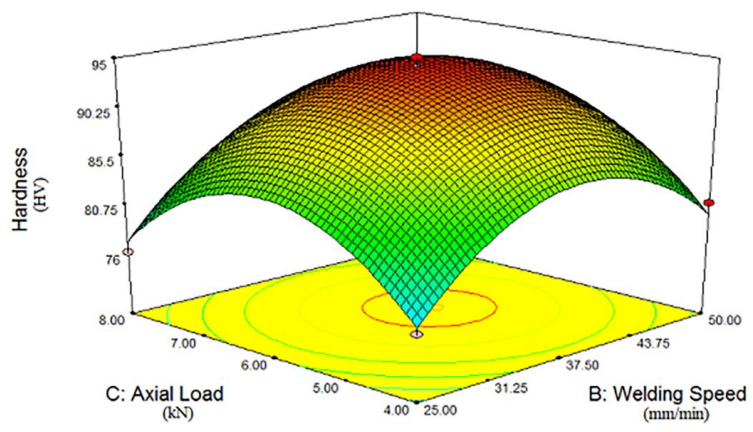

(b)

Fig. 10. Contour plots representing the effect of WS and AL on WNH: (a) 2D contour plot; (b) 3D contour plot.

composite material (AA6082/3\% $\mathrm{ZrO}_{2} / 5 \% \mathrm{~B}_{4} \mathrm{C}$ ). Fig. 13b clearly shows the presence of the four different zones (TMAZ, WNZ, HAZ, and unaffected zone). Fig. 13c to Fig. 13d show that the weld nugget zone has fine grain structure when compared to TMAZ, HAZ, and unaffected zone. It shows the presence of reinforcement particulates $\left(\mathrm{ZrO}_{2}\right.$ and $\left.\mathrm{B}_{4} \mathrm{C}\right)$ which act as a barrier to dendritic growth in the grain boundaries. A decrease in dendritic growth improves the UTS and microhardness of MMCs. It also shows the degree of accumulation of clusters and its growth with the addition of $\mathrm{ZrO}_{2}$ and $\mathrm{B}_{4} \mathrm{C}$ particulates provides strong strength to MMCs.

After the validation of results, the SEM analysis has been conducted on the fractured tensile specimen of $\mathrm{FS}$ welded $\mathrm{AA} 6082 / 3 \% \mathrm{ZrO}_{2} / 5 \% \mathrm{~B}_{4} \mathrm{C}$ MMC with optimum parameters. Fig. $14 \mathrm{a}$ to Fig. $14 \mathrm{c}$ indicate the SEM report of the microstructure of the fractured tensile specimen. It clearly shows the presence of a non-fractured surface region and fractured surface region. The fractured surface shown in Fig. 14a is further enlarged to $50 \mu \mathrm{m}$ and $100 \mu \mathrm{m}$ represented in Fig. 14b and Fig. $14 \mathrm{c}$, respectively and it shows the presence of dimples which are responsible for ductile fracture. The size of these dimples is smaller on the fractured surface of the stir zone compared to the base metal owing to the existence of hard and brittle reinforcement particulates like $\mathrm{ZrO}_{2}$ and $\mathrm{B}_{4} \mathrm{C}$ in the ductile aluminium matrix that employs constraints on the plastic flow of the matrix.

\section{Conclusions}

In this investigation, the optimization of FSW process parameters is performed for stir cast $\mathrm{AA} 6082 / 3 \% \mathrm{ZrO}_{2} / 5 \% \mathrm{~B}_{4} \mathrm{C}$ MMC's and the following conclusions are drawn:

(1) The three-factorial Box-Behnken experimental design has been successfully employed to develop the relationship between the responses (UTS and WNH) and input parameters (TRS, WS, and AL). Three levels in each parameter are selected and experiments have been carried out to optimize the UTS and WNH.

(2) Perturbation plot, 2D and 3D contour plots are developed and the interaction effects of welding parameters are analyzed. The TRS is the most 


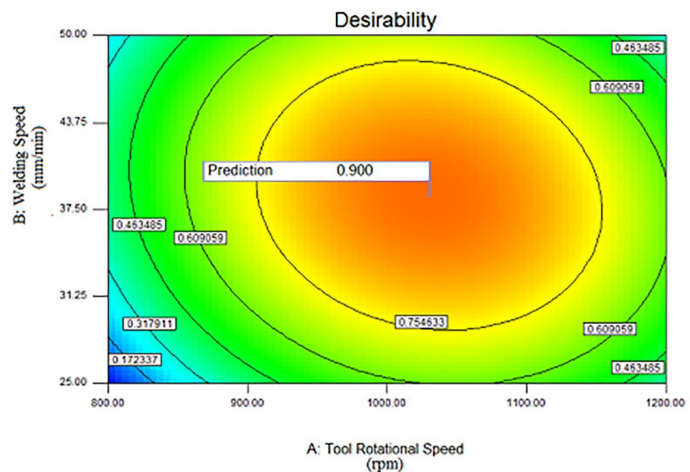

(a)

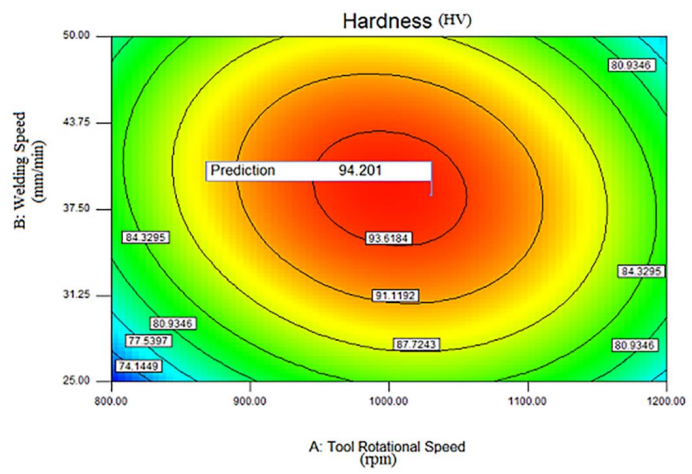

(c)

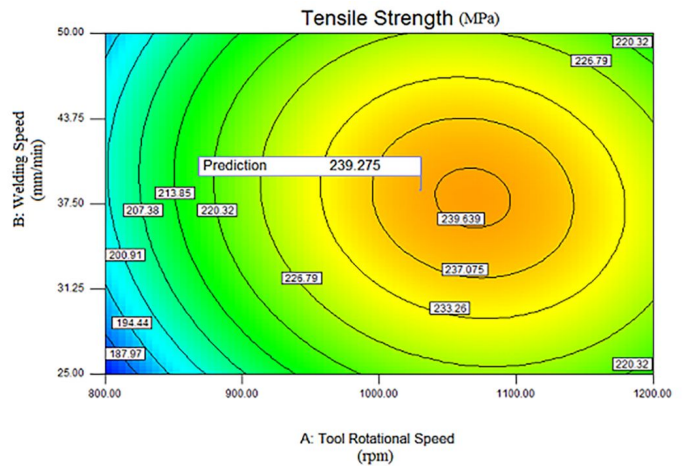

(b)

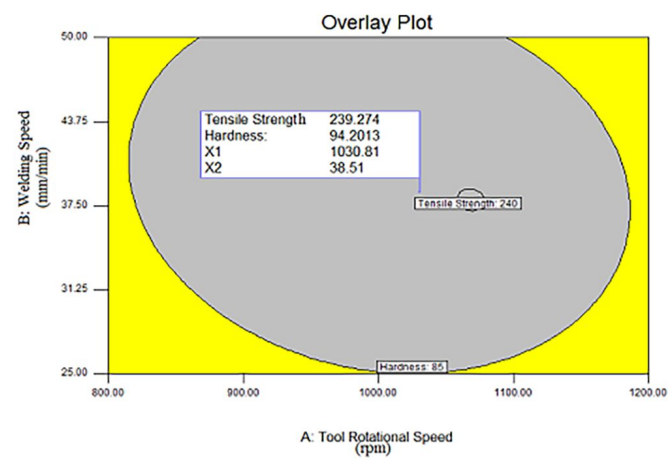

(d)

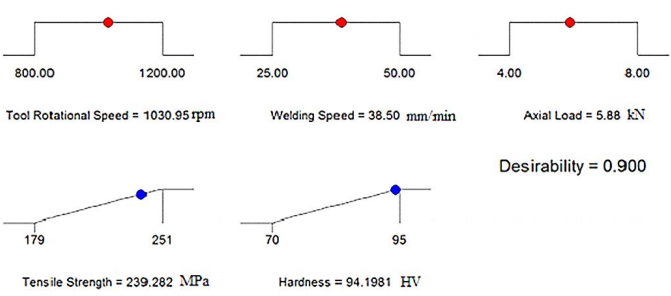

(e)

Fig. 11. Contour plots (a-c), overlay plot (d), and prediction plot (e) for the optimum UTS and WNH: (a) desirability plot; (b) 2D contour plot for prediction of UTS; (c) 2D contour plot for prediction of WNH; (d) overlay plot for 2D contour plot for prediction of UTS and WNH; (e) plot predicting the optimum FSW process parameters.

influencing parameter. The optimum UTS and $\mathrm{WNH}$ are found to be $240 \mathrm{MPa}$ and $94 \mathrm{HV}$, respectively, at corresponding welding conditions of TRS of $1000 \mathrm{rpm}$, WS of $37.50 \mathrm{~mm} / \mathrm{min}$, and AL of $6 \mathrm{kN}$.

(3) The desirability approach is further employed successfully from the results of all 17 experiments designed by the Box-Behnken method. The optimized results obtained are $239.27 \mathrm{MPa}$ for UTS and $94.203 \mathrm{HV}$ for $\mathrm{WNH}$ at the corresponding welding conditions of $1030.81 \mathrm{rpm}$ TRS, $38.51 \mathrm{~mm} / \mathrm{min}$ of WS, and $5.88 \mathrm{kN}$ of AL.

(4) The newly developed model is validated for UTS and WNH by comparing the results of all 17 experiments and predicted results for the same welding condition. The maximum percentage of error is -5.82 for UTS and -3.27 for WNH. It is confirmed that the newly developed model has 


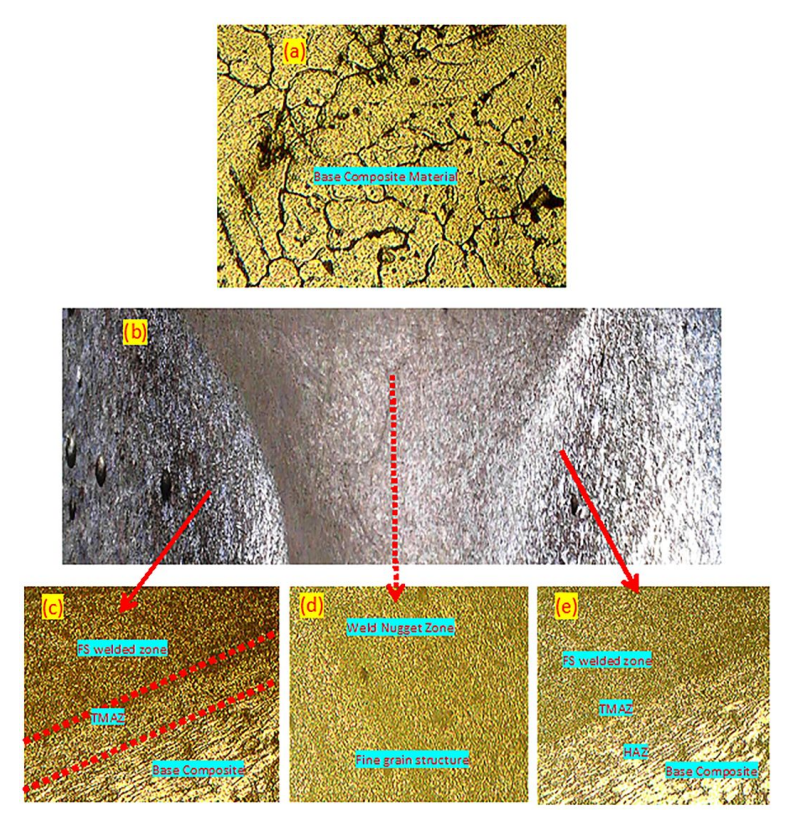

Fig. 12. (a) Microstructural analysis of base composite material, (b) macrostructural analysis of FS welded composite and (c-e) microstructural analysis of FS welded composite.
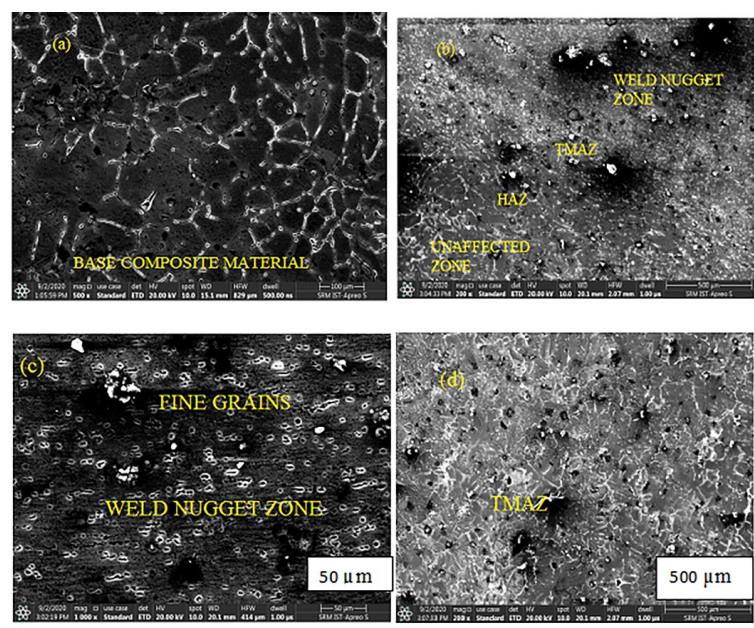

Fig. 13. (a-d) SEM analysis of base composite material and FS welded composite.

predicted the values of UTS and WNH very close to the experimental results.

(5) The microstructural and SEM analysis of FSW joints confirmed that the weld nugget zone has a fine grain structure when compared to TMAZ, HAZ, unaffected zone, and base composite material.

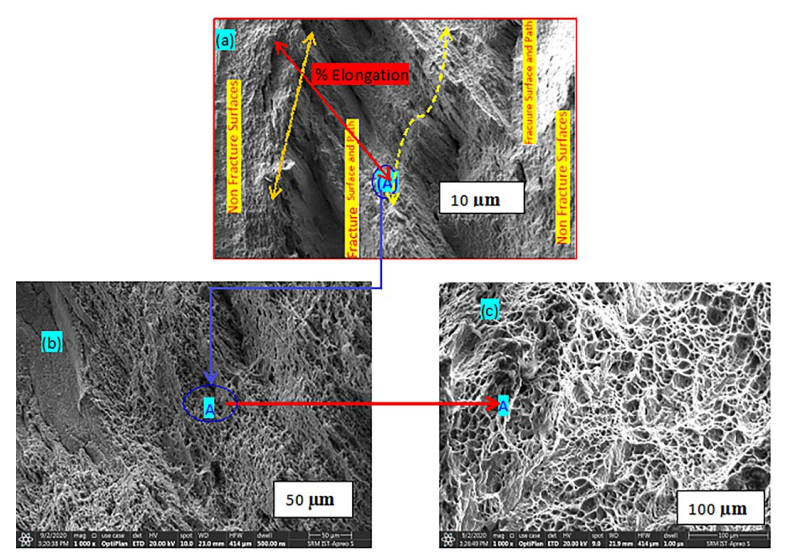

Fig. 14. SEM fractographic analysis for the tensile specimen of FSW joint.

\section{References}

[1] Prater T., Acta Astron., 93 (2014), 366.

[2] Parikh V.K., Badgujar A.D., Ghetiya, N.D., Mater. Manuf. Proc., 34 (2) (2019), 123.

[3] Mishra R.S., Mahoney M.W., Friction Stir Welding and Processing, ASM International, 2017, pp. $1-368$.

[4] Singh B.R, A Hand-Book on Friction Stir Welding, LAP LAMBERT Academic Publishing, 2012, pp. 1 248.

[5] Salih O.S., Ou H., Sun W., McCartney, D.G., Mater. Design, 86 (2015), 61.

[6] Dumpala D., Lokanadham L., Proc. Mater. Sci., 6 (2014), 1761.

[7] Mishra, R.S. JaIn, S., Int. J. Res. Eng. Innov., 3 (5) (2019), 301.

[8] Arab M., Zemri M., Mech. Mech. Eng., 22 (4) 2018, 1371.

[9] Khaki S., Heidari A., Kolahdooz, A., Int. J. Adv. Design Manuf. Technol., 12 (3) (2019), 25.

[10] ViJaYAN D., RaO V.S., J. Inst. Eng. India Ser. C, 95(2) (2014), 127.

[11] Bayazid S.M., Farhangi H., Ghahramani, A., Proc. Mater. Sci., 11 (2015), 6.

[12] Chanakyan C., Sivasankar S., Alagarsamy S.V., Dinesh Kumar S., Sakthivelu S., Meignanamoorthy, M., RaVichandran, M., Mater. Today Proc., 27 (2020), 707.

[13] Jain S., Sharma N., GuPTA, R., Eng. Solid Mech., 6 (1) (2018), 51.

[14] Periyasamy P., Mohan B., Balasubramanian V., Rajakumar S., Venugopal, S., Trans. Nonferrous Met. Soc. China, 23 (2013), 942.

[15] Ahmed K.E., Nagesh B.M., Raju B.S., DraKShayani D.N., Mater. Today Proc., 20 (2020) 108.

[16] Kumar B.A., Murugan, N., Mater. Design, 57 (2014), 383.

[17] Deepandurai K., Parameshwaran, R., Mater. Manuf. Proc., 31 (10) (2016), 1333. 
[18] Bhushan R.K., Sharma D., Adv. Comp. Lett., 28 [21] Sahu, M.K., Sahu, R.K., Intechopen, 1 (2019), 111. (2019), 1.

[19] Salih O., Ou H., Wei X., Sun, W., Mater. Sci. Eng. A, 742 (10) (2019), 78.

[20] Pandiyarajan R., Maran P., Murugan N., Marimuthu S., Sornakumar T., Mater. Res. Exp., 6 (6) (2019), 066553.

Received 2020-10-06

Accepted 2020-12-08 